\title{
Visual optimization analysis on e-commence of Wenzhou Hongwei commerce and trade
}

\author{
ZhiLiang Xia \\ Wenzhou Vocational \& Technical College, Wenzhou. 325035 \\ Xia441@sina.com
}

Keywords: E - commerce. Art designer. Visual optimization..

Abstract. This paper mainly introduces art design of e-commerce enterprises and improvement measures based on analysis of shop pages of Wenzhou Hongwei commerce and trade. Firstly it introduces the concept and main duty of art designer in e-commerce enterprises, analyzes shop pages of Wenzhou Hongwei commerce and trade daily necessities company, and put forward improvement countermeasures.

\section{Profile of enterprise and shop of Hongwei commerce and trade}

This paper analyzes shop pages of Hongwei commerce and trade, puts forward the measures to stable and increase market share, enhance profit ratio and brand image though optimize shop pages.

\section{Status analysis of pictures design of pages}

In analysis of shop pages of Hongwei commerce and trade, this paper mainly takes Tmall shop as an example, then looks for, analyzes problems and improves the conditions of the pages as shown in figure 1 


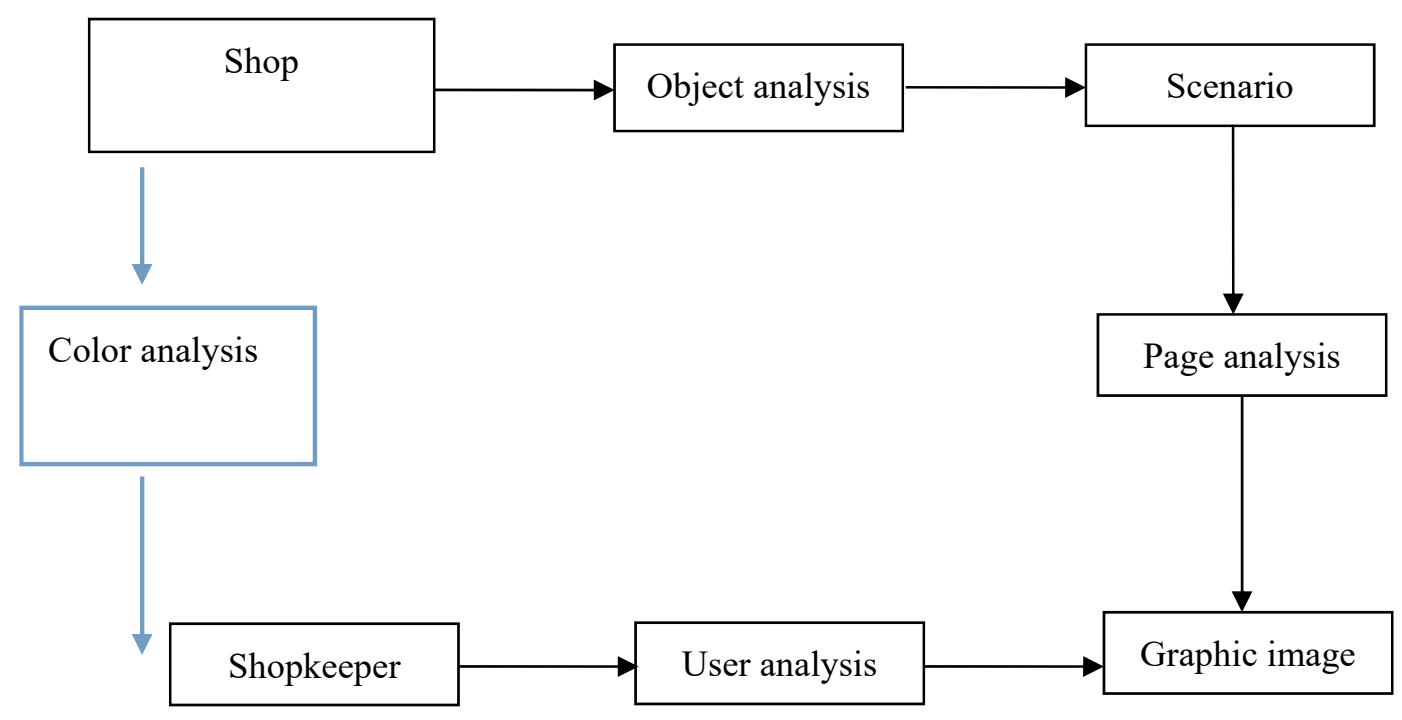

Figure 1 Analysis

\subsection{More attention on optimization of wireless end}

In the era of Internet, customers have been pursuing the first senses increasingly, if the first senses is good, high click and high conversion will follow. In art design industry, as a saying " 3 seconds vision" means how to catch customer's eyes in 3 seconds, attract customers' attention. The proportion of wireless end in Tmall has been higher and higher, and many similar shops have not paid more attention on wireless end visual optimization. Wireless end visual optimization is a great opportunity. Hongwei commerce and trade has focused on wireless end, it optimizes some conditions, such as no big enough font and unclear pictures after transferred them from PC end to wireless end. Wireless end has become a part of life, we should take the opportunity to develop it further.

\subsection{Our shop pages have no more advantages than that of competitors}

There are some strong competitors among many categories, compared to our various activities, such as promoting sales, they have been on the road developing their brands, such as Bcoole, Smell card, etc., and some offline brands also bring us tremendous pressure when they are online, such as Mr. Muscles. Our company's pages still have much difference from our strong competitors, we will not be able to develop our loyal users if we do not optimize pages timely. A company's development cannot avoid branding that our company will certainly embark on, and the page design will become an important factor, how to optimize the page will become an important indicator in development of enterprises. And these pages of strong competitors will be our goal to catch up and go beyond. 


\section{Current problems}

\subsection{Art designer team is lack of product awareness, and cannot grasp the customer pain points firmly}

Although e-commerce art designer team of Hongwei commerce and trade has excellent software technology in forefront of the industry, the entire art team is lack of product awareness. Hongwei commerce and trade e-commerce Company has no copy writer. Art designers have to do copywriting in most of time.

\subsection{Unclear core selling point}

A famous saying in marketing "You are not selling a drill but a hole" means that the products or services provided by enterprise are only tools or means to meet particular requirement for consumers. In my understanding, customers require one kind of product in fixed time and location, if we can meet their core needs, we can get some loyal users.

But in Hongwei commerce and trade shop pages, the proposed selling points have no big difference with that of other shops and they are not exclusive to our shop's core selling points, which will lead to our shop losing group of loyal users, when intensity of activities is less than other shops, sales will be surpassed quickly.

\subsection{No enough and close communication in the team}

In the daily work of Hongwei commerce and trade, everyone will work according to their own division, the operations pay attention to store data, and carry out a series of activities, art designers design and produce related pages, drills show, packaging..., Customer service staffs will be responsible to communicate with customers and solve a series of problems the customers meet in use.

Hongwei commerce and trade consists of some small shop teams, and each small team constitutes big team of Hongwei commerce and trade e-commerce. But it is not enough that each performs its own functions, members need to exchange ideas in small team, and a big team need everyone's effort to work together. However, in our daily work, lack of adequate communication between operators, art designers and customer service staffs may make art designer hard to understand sales conditions of the product. The information in the page detail may has some problems when customers use products in reality. Application scope may not be suitable for some products particularly. The operator is not particularly clear of the design problems the art designers encounter.

\subsection{Conclusion}

Although Hongwei commerce and trade company has skilled and active art designer team, has advantages in page update speed, pages design and other aspects, but the compared to the problems, advantages are not obvious, such as lack of product concept, hard to catch core selling points, no enough attraction to customers to be loyal customers, which will restrict the development of 
enterprises seriously. Most categories have been relative stable, if we still rely on activities and rebate, and no breakthrough on pages, we will have disadvantages of low profit and lack of work capital.

\section{Improvement countermeasures based on analysis}

Based on the above analysis of the problems in Hongwei commerce and trade e-commerce shop, there are some countermeasures and solutions to optimize pages and improve the data for the shop.

Raise the awareness of art designers on products to catch customers' pain points better.

\subsection{Free trial on products}

In the era of Internet, operation, visual optimization and communication are very important. But for a shop, the key is product, and best sales cannot sell lots of bad products. Our products have no problem in quality after layers of screening, and in this case, we need to enhance our understanding of the products. In the company, art designers can be given free products for trial to enhance their understanding of the products in product function, and solve the various design problems encountered in the design.

\subsection{Regular communication with customer service staffs}

Regular communication with customer service staffs make them understanding the problems of the product in the sales better, only communicate with direct customers, they can understand the customer's pain points and needs. And regular communication with the customer service staffs can also make the whole Hongwei commerce and trade team's ideas more consistent and strengthen teamwork spirit. In most of time, single person's thinking often cannot get stronger conclusion than that from communication. Only we continue to communicate and discuss often, we can reach consensus to solve the problem.

\subsection{Enhance communication between art designers and operators to promote page optimization capability}

The customer service staffs are easiest to see the pain points in daily communication with customers while operators know the product advantages best and the data clearest. In the team of Hongwei commerce and trade, in most of time, operators and art designers have very simple communication, such as product, time, picture and so on. Sometimes it is good to be simple and clear, but it will be lack of some idea exchanges between art designers and operators, art designers have no right to check the first-hand data and do not know how many clicks and transformation of the pictures he makes, all the changes on pictures relies on operators. But when they are lack of communication, art designers cannot optimize a page better and enhance the attractiveness of the entire shop.

Through communication, we can know our store's data, profit, click and transformation rate better, if the data goal cannot be reached, we will think about what the problems are, and which module on the page needs to be optimized. Only through continuous communication, we can know 
where the deficiencies are, which aspect needs to be improved, and then optimize shops, and enhance the page optimization capability.

\subsection{Continue to strengthen study to understand various cutting-edge design concepts}

E-commerce industry develops very fast with ever-changing. Although the art designer team of Hongwei is at high level, but it still has some defects, such as lack of product awareness, lack of communication in the team and so on. Art designers should continue to study after work has done, not only in application of software, but also in design ideas, product thinking and cutting-edge design.

\section{Summary}

Though visual analysis on pages of Wang Hongwei commerce and trade, we know that visual marketing of a good shop not only relies on skilled application of software, but also awareness and understanding of the products, mastery of cutting-edge design concept, mutual exchange and collaboration in the team. In the era of Internet, the product is still the core of a shop, but it is priority among priorities that how we highlight advantages of the products better, grasp customers' attention and enhance profitability of the company though visual marketing and page optimization.

\section{References}

[1] Mr. Medical equipment and humanized design [J].journal of mechanical design and research, 16 (5), 81-83

[2] ZhangShuYong [2], ZhangYaQing, QinQingHua. Discuss the humanized design heavy-tonnage loader [J].journal of engineering machinery, 2005 (12) : 32-36

[3] Chen ZhangDaWei Confucianism and full development mode of man-machine interface. Based on the analysis of the research and application [J], packaging engineering, 2007.28 (4), 113-115

[4] DingYuLan. Ergonomic (revised edition) [M].beijing: Beijing university press, 2006 